\title{
MANIZALES, CALDAS Y COLOMBIA GRAVITAN EN TORNO A LA UNIVERSIDAD
}

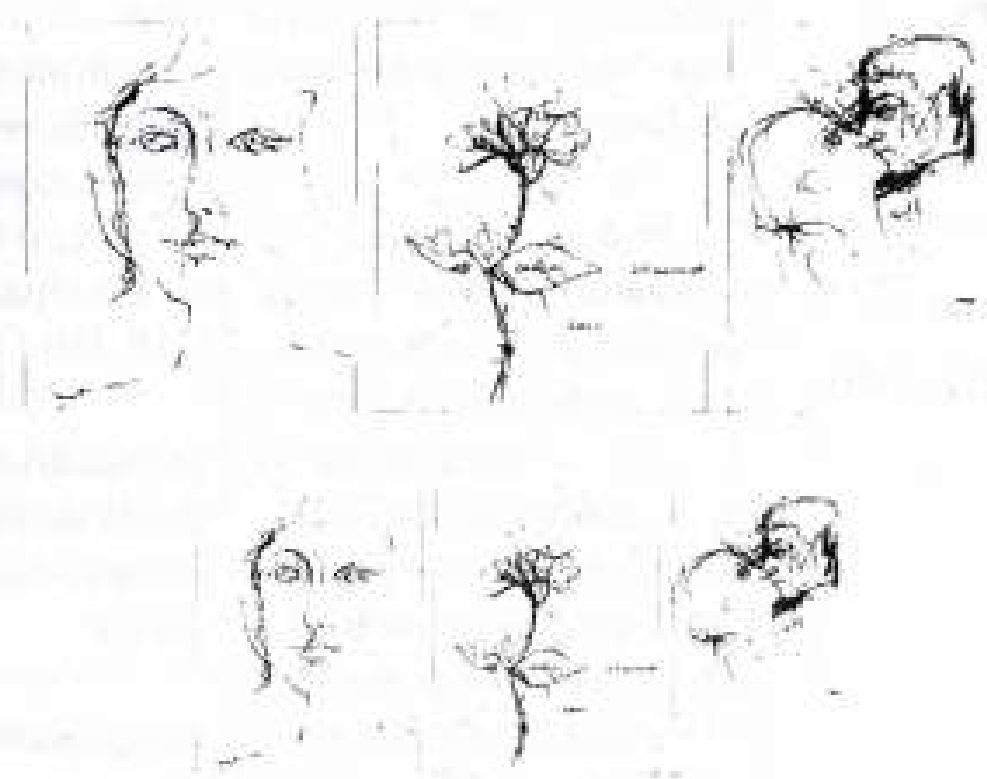

Presbitero L.FOPOLDOPELAEZ ARI3FL AFZ.

Presidente Consejo Superior

Universidad Autonoma de Manizales

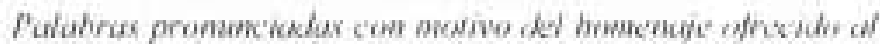

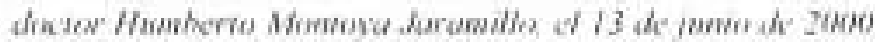
Nos congrega hoy una doble exigencia que es ni más ni menos lavida misma de la Universidad: Humberto Montoya Jaramillo, del grupo fundador de la Universidad Autónoma de Manizales ha terminado su Rectoria, y César Vallejo Mcjia. la inicia apenas.

Es para nosotros un deber ineludible y además go asso. agradecer a uno y otro su decisión tanto inicial. como el reto cumplido por Humberto. al dejar el campo abierto y ademàs regado por 
«Resulta de verdad suesfuerzo. Invilo, pues, a todos excitante trasegar estos caminos que otros ya recorrieron y llegar cansados, exhaustos pero libres $\mathbf{y}$ comprometidos con la transformación que nuestro mundo necesita.»

los presentes para que hagamos una expedición por lo que tiene que ser hoy la Universidad, teniendo en cuenta la velocidad y concreción del mundo moderno que exige demasiado: pero también los avatares que vive nuestra Patria Colombiana que está gritándonos clemencia.

¿Qué razón nos asiste para esta invitación tan peregrina'? Sencillamente que si no estamos empapados hasta la saciedad de la realidad que nos rodea. no podremos dimensionar la tarca cumplida por Humberto. la que apenas inicia César y lo que tiene que ser nuestro papel como (COMUNIDAD UNIVERSITARLA: VICErectorias, decanatos, facultades. profesores y alumnos, son centro vital de esta historia.

Manizales, Caldas y Colombia gravitan en torno a la Universidad poryue su fuerza vital está alli cuajada de ilusiones. Ilena de esperanzas y haciendo el camino de su realidad a través de la Academiarapoyada en la investigación? frutecida en obras que atinen a solucionar las dificultades que atraviesa la comunidad circundante.

Todo este quehacer se repite invariable en el esfuerzo a travís de generaciones, intentando solucio- nes a las purmanentes necesidadesdel pucblo al que servinos.

Resulta de verdad excitante trasegar estos caminos que otros ja recorricron y llegar cansiados, exhaustes pero libres y comprometidos con la transformacion yuc nuestro mundo necesita. Nunca hoy la universidad tiene que generar el esfuerzo que sea nucesario para dar los pasos en pos del concierto por cl bien. la bellezary la verdad.

Cuando la universidad se desentiende de su entorno, este cormienza a desmorunarse sin saber por qui.

He aqui puts amigas y amigos el compromiso que tenemos y al que tenemos que hacer frente $\sin$ dilacion y sin ahorrar esfier/o alguno.

La Universidad tiene que haeer hombres conscientes de su deher y del momento yue vive Colomhia. ciertamente grave, Perusiempre pasible de asumir con mente clara y corivin valiente.

No en vano la MISIOON de la universidad nos define como una

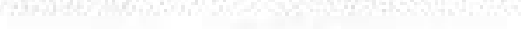

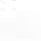

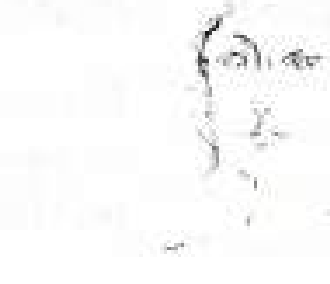


comunidad educadora. dinamizadora del conocimiento. comprometida con la convivencia pacifica y el desarrollo. que contribuye a la FORMACION DE PERSONAS ETICAS con pensamiento crítico e innovador.

Este hombre tiene que estar dotado de herramientas suficientes que le permitan hacer el cambio que todos percibimos y nadie asume de verdad como propio, tanto en lo POLITICO, COMO EN LO SOCIAL. Y EN LO ECONOMICO. Quiere decir esto que la tarea politica nos corresponde $y$ a fondo.

Llevamos décadas quejándonos, señalando flaquezas y debilidades. evitando los retos y desafios que trae la historia, con tal de pasar inadvertidos en la justa de los compromisos. Pensamos que la COSA PUBLICA pertenece a otros, y nosotros optamos por lo PRIVADO, quizís más rentable, de mayor aprecio en el medio y más honorifico en apariencia, Sin embargo, no puede ser asi. Ese modelo ya desgastó la nación. $\mathrm{La}$ sumió en el desprestigio y en la oscuridad, dejándola arrinconada

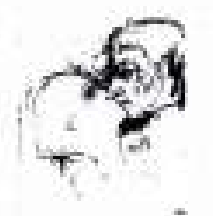

a su suerte que también nosotros vivimos.

Volvamos pues con honor y entereza a asumir lo NUESTRO. Estemos prestos a ventilar las soluciones que nos tocan. PONGAMOS EL PELLEJO para que levantando juntos de las cuatro puntas podamos llevar en al to el único estandarte posible: LA HONESTIDAD Y EL CRITERIO DEL BIEN COMUN. Esta empresa comunitaria del bien en forma alguna pertenece a unos cuantos. Es tarea permanente de todos. Más aún, quienes estamos en la Universidad, o bien porque en ella nos formamos, o bien porque a ella servimos, estamos colocados en lo alto, somos luz que senala la ruta. los caminos. $Y$ somos sin duda responsables del futuro.

Pero alli no se agota la exigencia. El bien, $y$ sobre todo el bien común que se impone casi por sí mismo, sólo es identificable en la VERDAD Y SOLAMENTE POR ELLA SE CONSIGUE.

Hemos entrado solemnemente en le nuevo MILENIO y lo hemos hecho de la mano del Pontifice JUAN PABLO II quien con su avasalladora personalidad $y$ testimonio de fe en la humanidad, nos ha puesto de frente a un mundo urgido por esa VERDAD. En su
«Este hombre tiene que estar dotado de herramientas suficientes que le permitan hacer el cambio que todos percibimos $y$ nadie asume de verdad como propio..." 
carta enciclicaEL ESPLENDOR DE LA VERDAD nos ha plasmado el modelo del hombre y del mundo que estamos en mora de ser y de lograr.

El bien y la verdad van de la mano de la belleza. Nuestro mundo es altamente susceptible a ella. La busca en todos los seres. Quiere sentirla en todos los actos humanos. La persigue siempre queriendola encontrar y poseer para siempre.

Lo bueno, lo verdadero y lo bello SUBYUGAN de modo particular al hombre. Lo definen. Lo hacen buscador infatigable de ellos. Aún, cuando equivocamos el camino. omitiendo estas categorias universales y nos atrevemos por las sendas equivocadas del mal, de la mentira y de la fealdad pensamos -equivocadamente claro está-, e intentamos también con ello lo bueno, la verdad y lo bello.
Ahora bien, no podemos quedarnos en la intención de encontrarlos y propiciar su realidad en nuestros actos y en nuestra vida. Es preciso pues poner lo que somos y tenemos para que el hombre modemo supere toda deficiencia que le impida ser bueno, hacer y vivir la verdad y obtener la belleza, cosa que no se hace posible sino en la medida en que el hombre sea de verdad universal como son dichas categorias, en la medida en que ese hombre sea de veras "Universitario".

Loa y prez sea dada a todos ustedes universitarios universales buscadores y hacedores del bien, de la verdad y la belleza supremos.

La tarea cumplida por Humberto merece la expresión de Pablo el Apóstol: "He concluido mi carrera. he combatido el buen combate. he conservado la fe". Entregas Humberto, la bandera para que César asuma el liderazgo y nos guie a buen puerto. AMEN
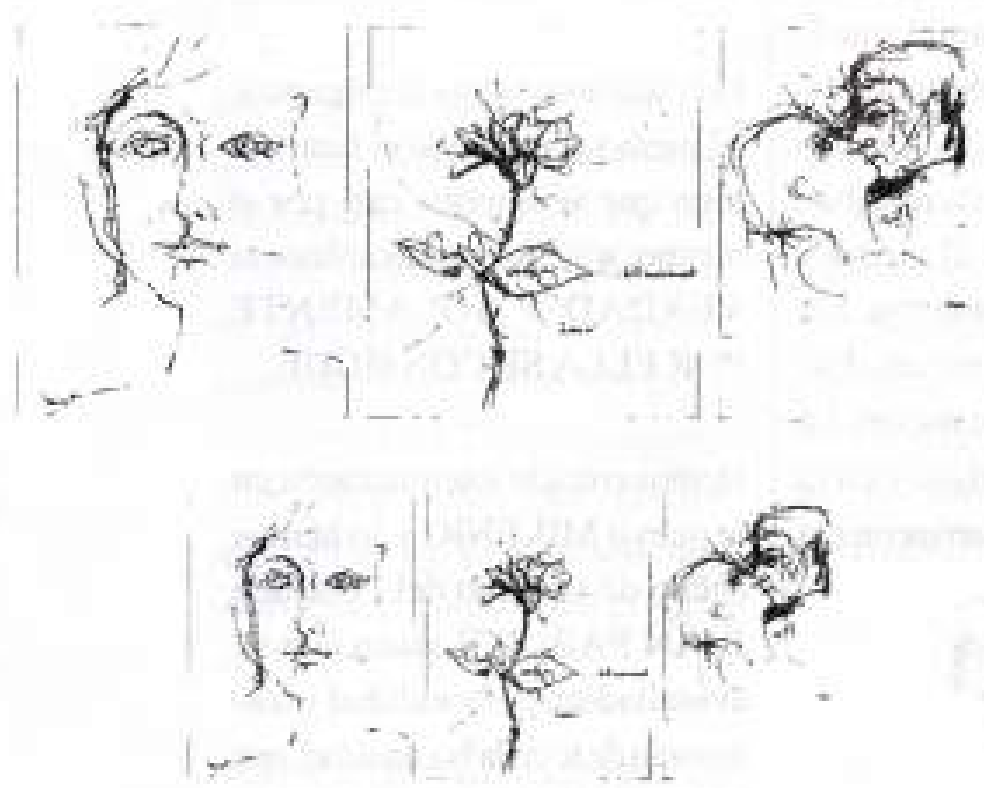